\title{
O processo de concretização do imaginário e a visitação no Parque Estadual do Jaraguá (SP)
}

\section{The process of concretion the imaginary and visitation in the Jaragua State Park (SP, Brazil)}

\author{
Bárbara Gambaré dos Santos, Airton José Cavenaghi
}

\begin{abstract}
RESUMO
Este artigo discute a compreensão do imaginário do visitante como um motivador para a visita ao Parque Estadual do Jaraguá - SP, além de analisar como ocorre essa experiência. A metodologia baseou-se em pesquisa exploratória de caráter bibliográfico com aplicação de entrevistas semiestruturadas acerca do imaginário, com os visitantes do Parque. $O$ estudo evidencia o crescimento da busca pelo contato com a natureza, que por meio de experiências e atividades de lazer e ecoturismo proporcionam sensações positivas para seus visitantes. Na conclusão das discussões apresentadas, observa-se que o imaginário pode servir de base para 0 planejamento e ações aplicada ao uso dos recursos naturais. A partir dos estudos e das pesquisas elaborou-se um gráfico analítico do Processo de Concretização do Imaginário, uma discussão teórica que permitiu visualizar como ocorre a experiência do visitante em relação ao contato com a natureza e o seu imaginário. O resultado da analise das entrevistas indicou, também, que não importa o local visitado, mas sim, o quanto de contato com a natureza a pessoa terá e quais sentimentos serão gerados a partir desta experiência, seja ela realizada no Parque Estadual do Jaraguá ou em outra área verde na qual as pessoas busquem a fuga da rotina diária dos grandes centros urbanos.
\end{abstract}

PALAVRAS-CHAVE: Turismo; Imaginário; Lazer; Parque Estadual do Jaraguá-SP. 


\begin{abstract}
This article discusses the understanding of the imaginary from visitor as a motivator for visiting the State Park Jaragua (SP, Brazill), analyzing how this experience occurs. The methodology was based on exploratory research with bibliographical and application of semi-structured interviews about the imaginary with visitors of the park. The study highlights the growing quest for contact with nature, that through experiences and leisure activities and ecotourism can provide positive feelings for visitors. At the conclusion of the discussions presented, it is observed that the imaginary can serve as a basis for planning and initiatives of sustainability applied to the use of natural resources. From the studies and the research was elaborated a graphic analytical of the Process Implementation of the Imaginary, a theoretical discussion that allowed visualization what occurs as the visitor experience in relation to contact with nature and your imaginary. The results of the analysis of the interviews indicated, too, that no matter the place visited, but rather, how much contact with nature, the person will have and what feelings are generated from this experience, whether held in the Jaragua State Park or another green area in which people seek to escape from the daily routine of the large urban centers.
\end{abstract}

KEYWORS: Tourism; Imaginary; Leisure; Jaraguá State Park (SP, Brazil).

\title{
Introdução
}

As áreas naturais que resistiram ao crescimento urbano, por exemplo, na cidade de São Paulo, são fragmentos de vegetação que em grande parte se tornaram áreas protegidas por lei, no caso do Brasil, por meio do Sistema Nacional de Unidades de Conservação (lei 9985/00), que possibilitou a padronização das denominações e suas formas de manejo. Dentre essas áreas destacam-se os Parques Nacionais, Estaduais e Municipais, locais que permitem a visitação pública e possuem infraestrutura básica e turística.

Esses remanescentes florestais exercem a manutenção da qualidade do meio urbano e oferecem espaço para o lazer, recreação e educação ambiental, além de possuírem um papel importante para o equilíbrio do clima, da conservação de mananciais e de espécies vegetais e animais (SMA, 1999).

Dentre as diversas áreas, destaca-se o Parque Estadual do Jaraguá (PE Jaraguá), uma unidade de conservação localizada a Noroeste do município paulista que possui o Pico do Jaraguá, o ponto mais alto da cidade com 1135 metros de altitude. Essa particularidade em relação aos demais parques proporciona uma visão panorâmica de $360^{\circ}$ graus da região metropolitana de São Paulo (Osasco, Guarulhos, Barueri, Jundiaí, Franco da Rocha, Caieiras, entre outros). Além disso, por ser um Parque Estadual, tem como função oferecer atividades de educação ambiental, lazer, recreação e turismo.

A crescente busca por lazer em áreas naturais tem como fator motivador o desejo de fugir da rotina diária, os moradores dos grandes centros urbanos estão em busca de novas experiências em contato com a natureza de maneira a satisfazer suas necessidades de lazer e fuga do cotidiano. Neste sentido, é possível perceber que o lazer em meio à natureza passou a ser algo necessário e fundamental para o ser humano. 
Ao longo da história as florestas foram sendo tomadas por mistérios em relação ao que poderia ser encontrado em seu interior. As lendas e os mitos que surgiram acabaram por despertar no cotidiano das pessoas um imaginário relacionado ao contato com a natureza.

Atualmente a busca por atividades de lazer em contato com a natureza geram expectativas, necessidades e aspiração para "encontrar" animais ainda não vistos, caminhar na mata com um sentimento de aventura, medo e adrenalina, imaginando situações diferentes da sua rotina, além da vontade de vencer desafios, como subir no topo de morros ou desbravar territórios. A busca por esse tipo de experiência se tornou cada vez mais comum e importante para o individuo.

Logo, é possível afirmar que o imaginário é um "motor" para a realização das ações humanas, deste modo, imaginar a fuga da rotina diária por meio do contato com a natureza se torna mais comum a partir do momento em que essa experiência deixa ser rotineira para aqueles indivíduos que moram nos grandes centros urbanos.

Esse desejo e a curiosidade de buscar o desconhecido tornam-se cada vez mais os motivos pelos quais os deslocamentos e as pesquisas científicas se intensificaram. A vontade de descobrir, se o que imaginava era verdade, tornou-se um grande desafio. $O$ homem passou a venerar as áreas naturais como algo precioso e um refúgio para se recuperar da vida caótica das grandes cidades. Isto é, a natureza possui características que tendem a despertar sentimentos bons ou ruins nas pessoas e o imaginário flui e cria a vontade de buscar esse contato com o "desconhecido".

Desta forma, o estudo do imaginário e a sua relação com a busca pelo contato com a natureza são relevantes, pois como "motor" para as ações humanas apontam os diferentes níveis de distanciamento entre o imaginado e o vivido e, até mesmo entre o que se pensa e o que se realiza em relação ao contato com a natureza.

A partir desta perspectiva de análise, o objetivo geral deste estudo foi compreender o imaginário do visitante como um motivador para a visita ao Parque Estadual do Jaraguá, e como ocorre essa experiência.

Para alcançar o objetivo geral, o estudo propôs os seguintes objetivos específicos: a) Compreender a relação entre o imaginário e a concretização da experiência do visitante no PE Jaraguá; b) Compreender o imaginário do visitante em relação ao PE Jaraguá; c) Entender a relação do imaginário com a motivação para a visita ao PE Jaraguá.

O problema da pesquisa indica os seguintes questionamentos: $O$ imaginário do visitante é um motivador para a visita ao Parque Estadual do Jaraguá? Como se da à experiência do visitante ao visitar o Parque Estadual do Jaraguá?

A hipótese pertinente a esta pesquisa compreendem o imaginário do visitante em relação ao PE Jaraguá como um fator motivador, pois se manifesta em função da busca do contato com a natureza e a sensação de fuga do cotidiano e da rotina nos centros urbanos se dá a partir das experiências vivenciadas em contato com a natureza. 
A metodologia utilizada para o alcance dos objetivos baseou-se em pesquisa qualitativa com entrevistas semiestruturadas.

Foram realizadas 30 entrevistas em três dias (dois domingos e um feriado), nos dias 29 de abril, 01 e 06 de maio de 2012, sendo que a escolha das datas foi proposital em função do número de visitantes que o parque recebe aos finais de semana e feriados.

Os locais de abordagem dos visitantes ficam nas dependências do PE Jaraguá, parte baixa (área de churrasqueiras, playgrounds, área para piquenique e trilha) e parte alta (Pico do Jaraguá, trecho final da trilha do Pai Zé, mirantes e pista). As 30 pessoas foram abordadas aleatoriamente, sendo que as entrevistas foram gravadas com a autorização dos visitantes e seus nomes foram preservados, garantindo-se o anonimato dos depoentes. A duração média das entrevistas foi de cinco minutos por pessoa.

Vale ressaltar a importância da abordagem inicial das entrevistas que esclarece 0 objetivo da pesquisa e preconiza 0 anonimato dos entrevistados, a fim de tornar a entrevista um momento de liberdade de expressões, pensamentos e sentimentos que corroboram para o alcance dos objetivos geral e específicos.

Neste contexto foram feitas cinco perguntas chave que permitiram aos entrevistados falarem livremente sobre 0 assunto sem que 0 pesquisador influenciasse ou manipulasse suas respostas: "Como tomou conhecimento do Parque?"; "Quanto tempo frequenta o Parque?"; "Por que escolheu visitar o Parque hoje?"; "Qual atividade você buscou fazer aqui no Parque?"; "O que você sente ao entrar aqui no Parque?" e "O que o Pico do Jaraguá representa para você?".

A utilização de entrevista revelou-se um instrumento de coleta de dados de maior flexibilidade para a investigação proposta, deste modo tornando-se relevante deixar o entrevistado a vontade para responder e a partir daí estruturar as resposta para elucidar as questões de pesquisa abordadas e alcançar os objetivos propostos a fim de contribuir para a compreensão da temática.

\section{O Imaginário e a busca pela natureza}

O imaginário é algo que sempre esteve presente no cotidiano humano impulsionando-o para o desenvolvimento e a busca pelo desconhecido. É um tema essencial a ser estudado, pois complementa e reflete os caminhos que a humanidade vem seguindo, demonstrando seus medos, seus desejos e seus sonhos. Neste sentido, relacioná-lo com 0 contato com a natureza se torna relevante devido à uma "reaproximação" do homem urbano com essa "nova descoberta", a natureza.

A urbanização e a tecnologia provocou um distanciamento das áreas naturais fazendo com que se tornassem locais de refúgio e contemplação para homem, gerando curiosidades, expectativas e fantasias a partir de um imaginário voltado ao contato com a natureza.

O imaginário para Silva (2003, p.4) "é uma fonte racional e nãoracional de impulsos para a ação, é também uma represa de sentidos, de 
emoções, de vestígios, de sentimentos, de afetos, de imagens, de símbolos e de valores". Todos esses fatores podem ser relacionados com o que a natureza passou a provocar no imaginário humano nas últimas décadas, ou seja, veneração, apreciação, e contemplação.

Ainda Silva (2003), afirma que o imaginário é um "reservatório/motor", ou seja, ao mesmo tempo em que guardamos sentimentos, imagens, experiências, lembranças, etc., temos um "motor" que impulsiona para a ação de concretizar o que foi imaginado, e esse processo ocorre individualmente ou em grupo.

Le Goff (1994, p.16), afirma que "o imaginário alimenta o homem e fálo agir. É um fenômeno coletivo, social e histórico". Neste sentido, é possível compreender que é o imaginário relacionado ao contato com a natureza que faz com que cada vez mais pessoas são impulsionadas a buscarem esses espaços naturais "desconhecidos" para vivenciar novas experiências.

Acrescentando a essa discussão Wunenburger (2007, p.12), afirma que os "[...] diferentes constituintes de um imaginário (tempo, espaço, personagens, ação etc.) podem dar, depois de uma interpretação, indicações valiosas sobre o sujeito imaginante que se serve desses operadores para exprimir afetos, idéias, valores [...]", ou seja, essas interpretações devem ser feitas mediante o contexto social, econômico, político, geográfico, histórico, etc.

Esses constituintes apresentados pelo autor podem ser facilmente relacionados com o homem e a busca pela natureza e como seu contexto social pode influenciar a vivência em meio à natureza, ou seja, um "(...) ecossistema é um reservatório de informações" (DEAN, apud CAVENAGHI, 2001).

Como exemplo podemos citar os moradores dos grandes centros urbanos que possuem acesso aos diversos tipos de tecnologias, saneamento básico, ofertas de diversos produtos, além de trânsito, poluição visual, sonora e do ar, entre outros, que influenciam, de certa maneira, a forma de se relacionarem e usarem apenas como fonte de lazer os recursos naturais, diferentemente dos moradores rurais que ainda possuem fortes laços com os recursos naturais como fonte de sobrevivência.

Logo, o imaginário que produz a imagem que temos do mundo, portanto, pode-se pensar que quanto mais o homem urbano imaginar 0 contato com a natureza, mais apegado e ligado a ela ficará. Neste sentido, acredita-se que estimular esse imaginário será uma forma de incentivar a minimização dos impactos ambientais negativos e promover o aumento da conscientização ambiental e a valorização da natureza.

Em vista disso, observa-se que a busca pelo imaginário está relacionado constantemente com novos desafios em todos os momentos da evolução humana, seja nas profundezas dos oceanos, interiores das cavernas e das florestas e para além do planeta. $O$ desejo e a curiosidade humana de buscar o desconhecido se tornam cada vez mais intensas, motivando os deslocamentos e as pesquisas científicas. Descobrir se o imaginado é verdade ou é possível conceber é o grande desafio e o 
interesse pelo desconhecido sempre gera incertezas, ilusões, desejos, esperanças e medos. Como explica Gastal (2003, p.57):

Viagens e imaginário sempre andaram juntos, daí sua importância para o turismo. Enfrentar o desconhecido, ou simplesmente adentrar o novo, causa certa instabilidade nas pessoas. Assim, o espaço desconhecido será ocupado pelos sentimentos das pessoas em relação a ele, sentimentos que serão materializados de diferentes maneiras em diferentes momentos históricos.

Todavia, o imaginário e o desejo existente de desvendar os mistérios em torno da natureza retornam hoje como uma forma de lazer, e não apenas como uma fonte de sobrevivência. Essas áreas naturais se tornaram espaços estruturados (banheiros, lanchonetes, trilhas, sinalização etc.), para atender uma demanda crescente que imagina e tem interesse em ter momentos de contato com a natureza para fugir do cotidiano urbano.

A urbanização e a tecnologia acarretou um distanciamento das áreas naturais fazendo com que se tornassem locais de refúgio e contemplação para homem, provocando curiosidades, expectativas e fantasias a partir de um imaginário voltado ao contato com a natureza.

Deste modo, identificou-se que entre o imaginado e o concretizado existem etapas, que nesse estudo denominou-se de Processo de Concretização do Imaginário - PCI (Figura 1) que surgem a partir de quatro momentos: Imaginar; Planejar; Concretizar; e Consequências.

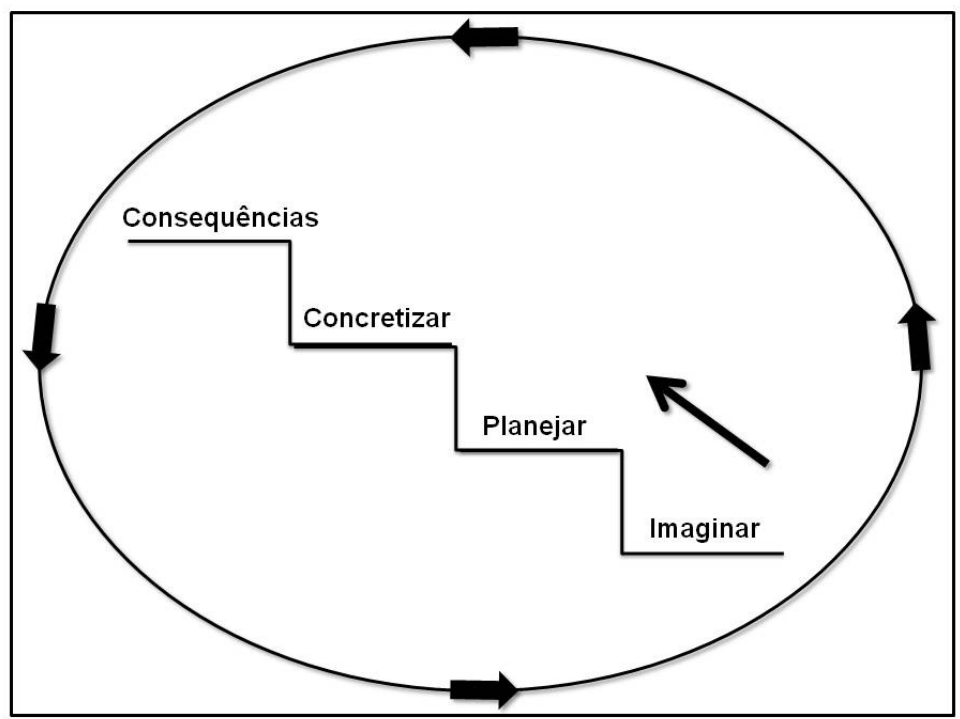

Figura 1: Processo de Concretização do Imaginário - PCI.

Figure 1: Process of Concretion Imaginary.

Fonte: Elaboração própria (2012). Source: authors. 
Os elementos do $\mathrm{PCl}$ possuem o mesmo grau de importância, pois determinam os estágios que cada pessoa passa ao dar início para concretizar seu imaginário. Cada "degrau" alcançado determina um passo para o estágio seguinte, ou seja, um alimenta o outro para gerar motivação e força para se atingir o próximo "degrau" e finalmente concretizá-lo totalmente ou parcialmente, pois se sabe que nem tudo o que é imaginado é possível reproduzir na realidade. Esse processo é infinito visto que as motivações também são infinitas.

Cada "degrau" é um processo a ser realizado pelo indivíduo. Seu início é no imaginário e a partir disso investe-se no planejamento para concretizar o desejado, material ou imaterial, como última etapa surge às consequências positivas ou negativas.

A elaboração desse esquema auxiliou as análises das entrevistas e a obtenção dos resultados quanto as seguintes hipóteses: a) o imaginário do visitante em relação ao PE Jaraguá é um fator motivador, pois se manifesta em função da busca do contato com a natureza; e b) a sensação de fuga do cotidiano e da rotina nos centros urbanos se dá a partir das experiências vivenciadas em contato com a natureza.

\section{Caracterização do Parque Estadual do Jaraguá}

O PE Jaraguá é uma Unidade de Conservação (UC) administrada pela Fundação para a Conservação e a Produção Florestal do Estado de São Paulo - Fundação Florestal (FF), órgão vinculado à Secretaria de Meio Ambiente do Estado de São Paulo (SMA). Declarado como Patrimônio da Humanidade pela UNESCO (Organização das Nações Unidas para a Educação, a Ciência e a Cultura), na qualidade de Reserva da Biosfera, passando a integrar a Zona Núcleo do Cinturão Verde da Cidade de São Paulo.

Tem como objetivo promover a integração com a comunidade local de forma a lhe proporcionar, por meio da proteção e recuperação dos recursos naturais, o incentivo à pesquisa científica, a promoção da educação ambiental, o lazer e a prática de atividades de ecoturismo (FFLORESTAL, 2010).

Os parques localizados nas áreas urbanas ou próximos a elas possuem um papel fundamental para a vida dos habitantes das cidades. Esses remanescentes de áreas verdes exercem manutenção da qualidade do meio urbano proporcionando o equilíbrio do clima, da conservação de mananciais e de espécies nativas, além de oferecem espaços para o lazer, recreação e educação ambiental (SMA, 1999). Naturalmente esses parques acabam estimulando a visitação pública, seja por curiosidade, fantasia ou aventura, o imaginário esteve presente na escolha por uma atividade em meio à natureza.

O PE Jaraguá (Figura 2), área com 492,68 ha de Mata Atlântica, que está localizado no município paulista, a $16 \mathrm{Km}$ do marco zero na Praça da Sé, destaca-se dos demais parques por possuir o ponto mais alto do município paulista, o Pico do Jaraguá, com 1135 metros de altitude (FFLORESTAL, 2010). 


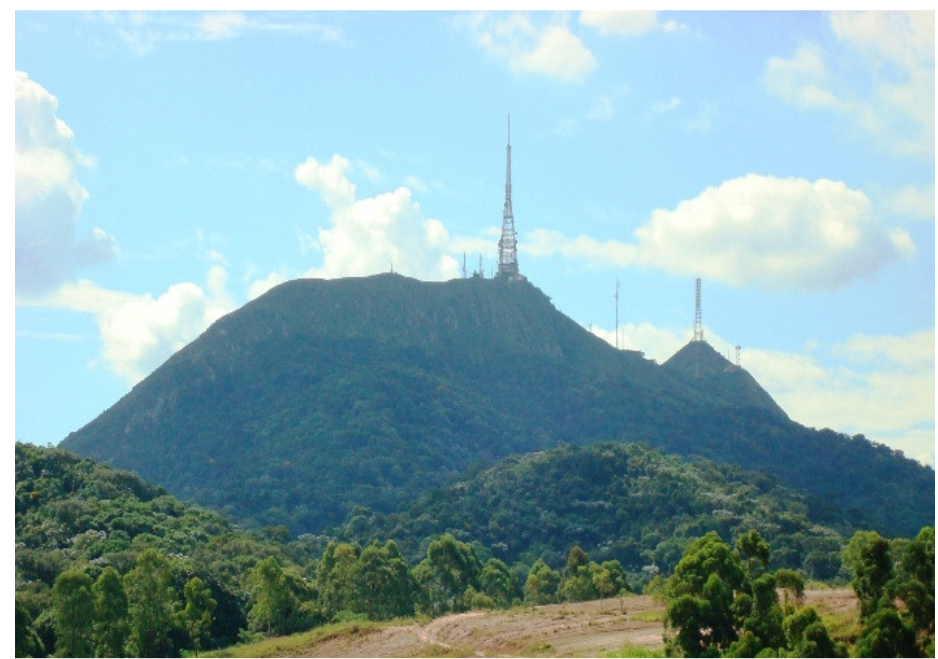

Figura 2: Pico do Jaraguá visto do bairro de Pirituba.

Figure 2: Pico do Jaragua viewed of district Pirituba.

Foto: B. Gambaré (2012). Photo: B. Gambaré (2012).

$\mathrm{Na}$ área de uso intensivo do $\mathrm{PE}$ Jaraguá existem quatro trilhas autoguiadas: Lago (Figura 3), destinada a todo tipo de público por possuir grau de dificuldade baixo, sua extensão é de 969 metros (ida e volta), com estimativa de duração de 20 minutos; Silêncio (Figura 4), totalmente adaptada para atendimento de pessoas deficientes seu percurso tem duração de 30 minutos em média e sua extensão é de 828 metros (ida e volta) com o grau de dificuldade baixo, ambas possibilitam a contemplação da fauna e flora sem dificuldades.

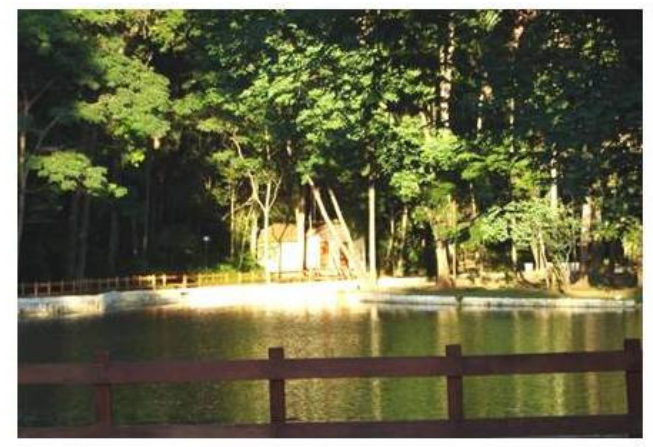

Figura 3: Trilha do Lago.

Figure 3: Trail of Lago.

Foto: B. Gambaré (2010).

Photo: B. Gambaré (2010).

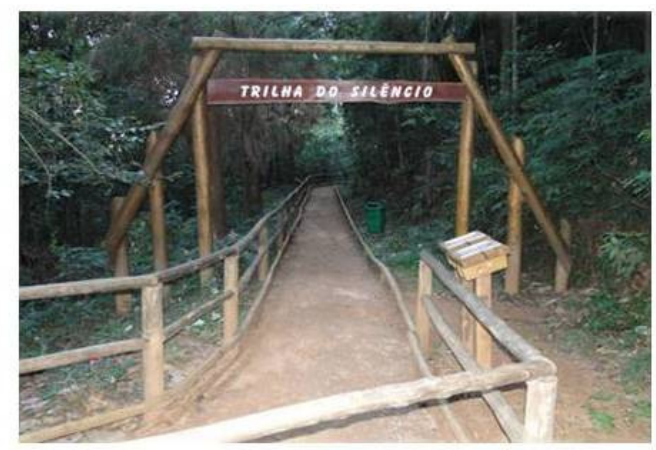

Figura 4: Trilha do Silêncio

Figure 4: Trail of Silêncio.

Foto: B. Gambaré (2011).

Photo: B. Gambaré (2011).

Quanto à trilha da Bica (Figura 5), sua extensão é de 800 metros (ida e volta), seu percurso tem duração de 45 minutos e o grau de dificuldade é médio; Pai Zé (Figura 6): sua extensão é de 1600 metros (ida e volta), seu percurso tem duração de 60 minutos e o grau de dificuldade é alto. A trilha do Pai Zé é a única a dar acesso ao Pico do Jaraguá, ao percorrer essa trilha é possível observar a mudança de vegetação de Mata Atlântica para Campo de Altitude. 


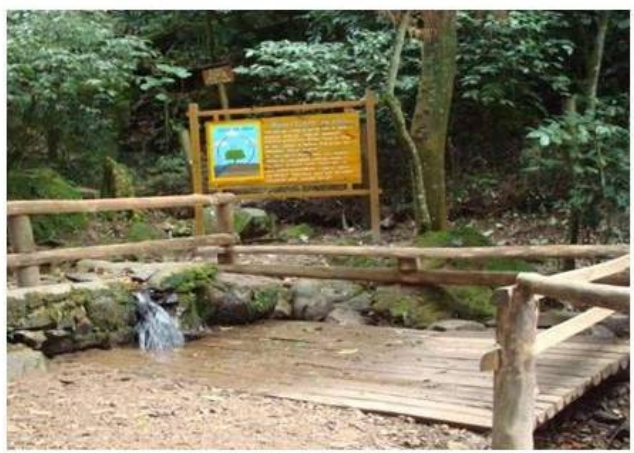

Figura 5: Trilha da Bica.

Figure 5: Trail of Bica.

Foto: B. Gambaré (2011).

Photo: B. Gambaré (2011).

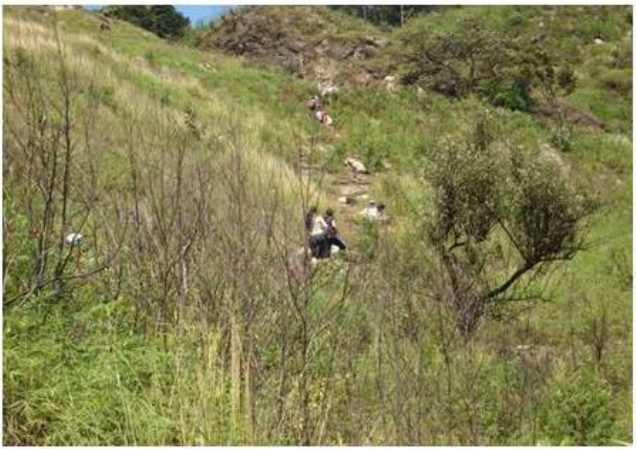

Figura 6: Trilha do Pai Zé. Figure 6: Trail of Pai Zé.

Foto: B. Gambaré (2011).

Photo: B. Gambaré (2011).

Além das trilhas, o parque possui infraestrutura que envolve anfiteatro, banheiros e lanchonetes, essas instalações são datadas da década de 70 quando deu início ao processo de construção do Complexo Turístico do Jaraguá.

A flora do parque encontra-se em uma área de transição onde predomina a formação da Mata Atlântica (Floresta Ombrófila Densa'1), que apresenta mata densa e úmida, com altura média de 15 metros, mas com árvores de até 40 metros de altura e um rico sub-bosque ${ }^{2}$ composto por diversas espécies como orquídeas, bromélias, samambaias-açú e árvores maiores como as araucárias, o cedro rosa, o palmito juçara, o pau jacaré, pau-brasil e guapuruvus, entre muitos outros (Figura $7 \mathrm{~A}-\mathrm{H}$ ). E, na parte superior, área próxima do cume do Pico do Jaraguá, identifica-se mudanças de vegetação, deixando de árvores altas para arbustos, denominando-se com características de cerrado (FFLORESTAL, 2010).

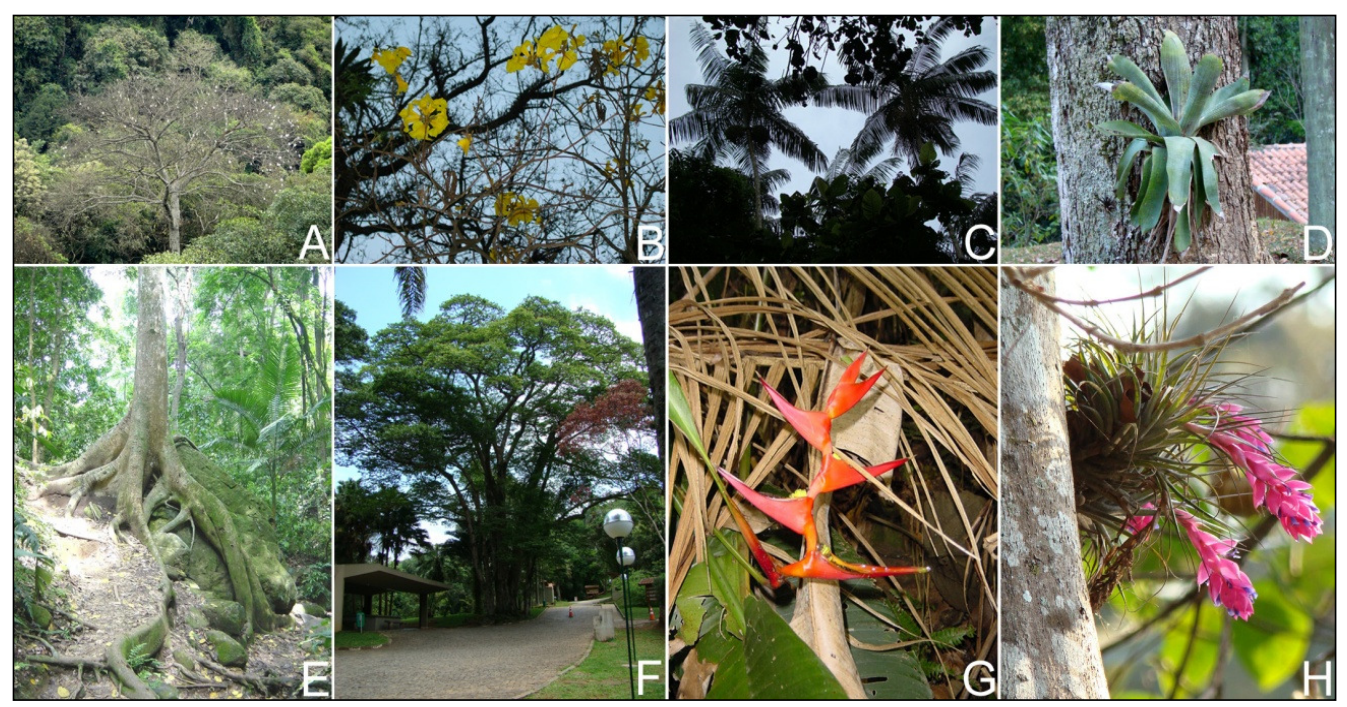

Figura 7 A-H: Flora do Parque Estadual do Jaraguá. A. Paineira; B. Ipê-amarelo; C. Palmito-juçara; D. Bromélia; E. Figueira; F. Jatobá; G. Heliconia; H. Bromélia.

Figure 7 A-H: Flora of Jaragua State Park. A. Paineira; B. Ipê-amarelo; C. Palmito-juçara; D. Bromélia; E. Figueira; F. Jatobá; G. Heliconia; H. Bromélia.

Fotos: RP Indicatti (2007-2011). Photo: RP Indicatti (2007-2011). 
Quanto sua fauna é possível identificar diversas espécies nativas de florestas de Mata Atlântica com uma grande diversidade de animais, dentre eles os mais comuns são: aves (biguá-preto, socozinho, sabiá laranjeira, Martim-pescador, pica-pau-de-banda-branca, tucano-do-bico-verde; mamíferos: capivara, quatis, veado-mateiro, bicho-preguiça, gambás; répteis: cascavel, jararaca, lagarto teiú, coral verdadeira e falsa, camaleãozinho, cobra cipó, entre outros (Figura 8 A-L).

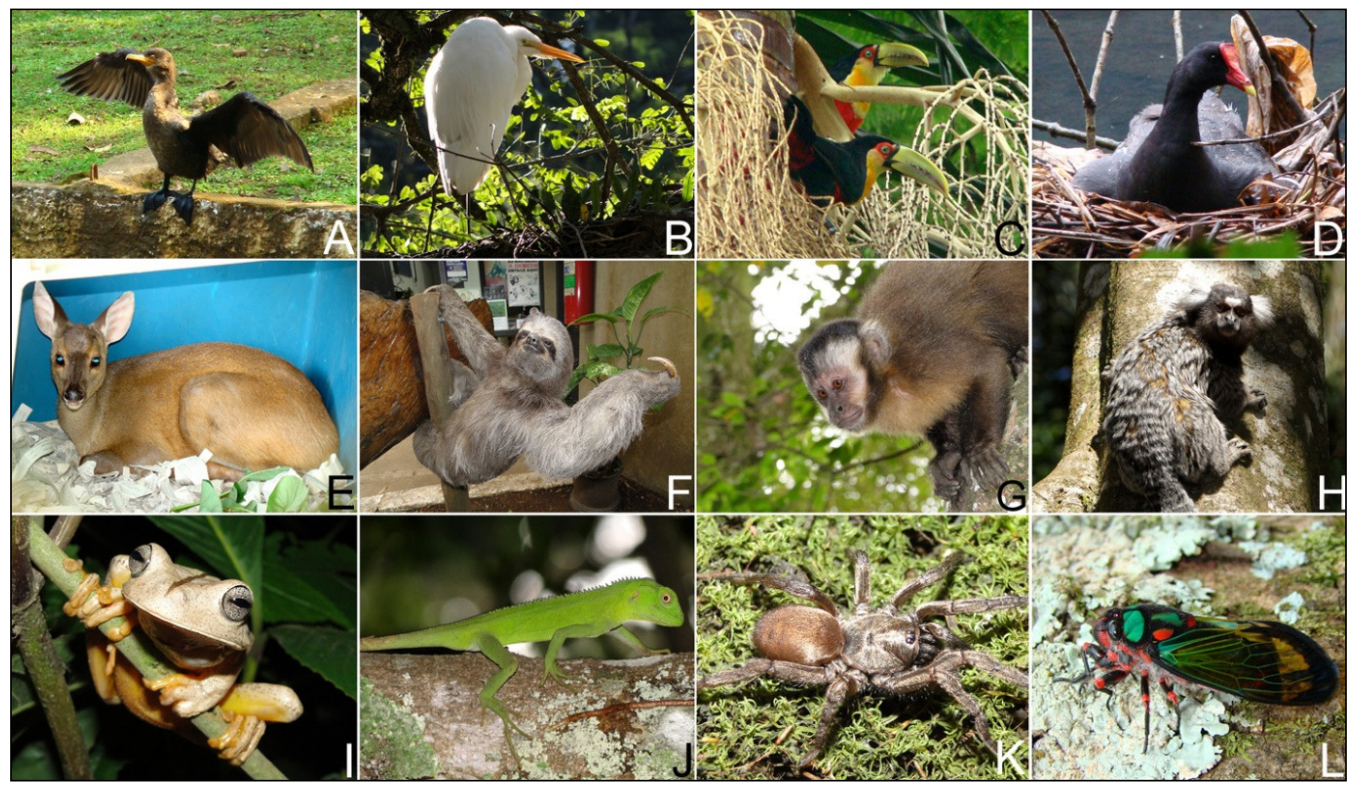

Figura 8 A-L: Fauna do Parque Estadual do Jaraguá. A. Biguá; B. Garça-branca-grande; C. Tucano-do-bico-verde; D. Frango-d'água; E. Veado-catingueiro; F. Bicho-preguiça; G. Macaco-prego; H. Sagui-do-tufo-branco; I. Perereca; J. Camaleãozinho; K. Aranhacaranguejeira; L.Cigarra.

Figure 8 A-L: of Jaraguá State Park. A. Biguá; B. Garça-branca-grande; C. Tucano-do-bicoverde; D. Frango-d'água; E. Veado-catingueiro; F. Bicho-preguiça; G. Macaco-prego; H. Sagui-do-tufo-branco; I. Perereca; J. Camaleãozinho; K. Aranha-caranguejeira; L.Cigarra. Fotos: RP Indicatti (2007-2011). Photo: RP Indicatti (2007-2011).

Segundo dados do Plano de Manejo (FFLORESTAL, 2010) os atrativos turísticos do PE Jaraguá, são: o Pico do Jaraguá, Pico do Papagaio, Casarão do bandeirante Afonso Sardinha (datado de 1580), Tanque de lavagem de ouro, lagos, tanque batismal (usado por evangélicos), Auditório Jessica Nunes Herculano, Trecho de escalada, Estrada Turística do Jaraguá (trecho que fica dentro do parque) e complexos de churrasqueiras.

Ao identificarem-se os atrativos do parque fica evidente porque sua demanda aos finais de semana e feriados aumenta consideravelmente, além disso, é um dos poucos parques estaduais que possui área com churrasqueiras, quadras poliesportivas, playgrounds e pista de skate. Duas pesquisas realizadas em 2008 e 2010 demonstraram que o principal uso do parque pelos seus visitantes é caminhar nas trilhas e realizar churrasco com seus familiares e amigos (GAMBARÉ, 2011).

As características geográficas do PE Jaraguá sempre atraiu a atenção das pessoas, desde os indígenas em tempos remotos, 
bandeirantes a caminho do sertão do Brasil, aeronaves como rota para pouso e decolagem e transmissões de sinais de televisão, celular e rádio.

No contexto histórico de uso da área, observa-se que o PE Jaraguá é um local destinado à conservação da natureza, mas também é uma área destinada às atividades de lazer e turismo, por isso, diversos estudos são relevantes, principalmente aqueles relacionados a demanda, impactos positivos e negativos, sua fauna e flora, áreas de uso público, entre outros, para que se mantenha sua proteção e sua conservação.

\section{Do imaginado ao vivenciado no Parque Estadual do Jaraguá}

A compilação, análise e estudo das ideias propostas pelos autores referenciados, detectou-se que o imaginário ocorre por meio de um processo conforme o esquema apresentado anteriormente denominado de $\mathrm{PCl}$ (Figura 1). Com o confronto entre as perguntas feitas nas entrevistas, as respostas dadas pelos entrevistados e o PCl foi possível detectar 0 imaginário do visitante em relação ao PE Jaraguá e compreender esse imaginário como um motivador para a visita ao parque e como ocorreu essa experiência.

A primeira etapa do $\mathrm{PCl}$ - Imaginar foi identificada a partir da pergunta "Por que escolheu visitar o parque?". Identificou-se que as declarações dos entrevistados remeteram-se ao imaginário da busca pelo contato com a natureza e a importância de respirar um ar mais puro e a quebra da rotina diária. Conforme declarações: Bom... Um pouco de verde que tem e que a gente tem que preservar. Ainda é um ar puro e isso é bom, meu físico e meu bem estar (Entrevistado 9); Eu venho mais pra quebrar a rotina diária (trabalho e faculdade), descansar, relaxar, respirar ar puro (Entrevistado 30).

As respostas representam o imaginário do homem urbano em relação à natureza e o seu distanciamento gerou a motivação em buscar essas sensações que não vivenciam diariamente.

A primeira etapa também é reforçada por meio da pergunta: "O que o Pico do Jaraguá representa para você?". Os entrevistados deram as seguintes declarações: Saúde, sossego, harmonia, é um lugar bem sossegado, né! Muito verde, tudo o que não tem lá fora nas avenidas e a poluição (Entrevistado 1); Um pedaço que ainda temos que preservar. Eu me sinto muito bem aqui e pensar que um dia tudo foi assim (Entrevistado 13); Um pedacinho da natureza, uma parte de São Paulo que não podemos perder. É tão pequeno e tão importante (Entrevistado 21).

Para Silva (2003), o imaginário é uma fonte de emoções, sentidos, afetos, sentimentos e valores. Logo, identificou-se que o PE Jaraguá se revela como sendo fonte de saúde, harmonia, sossego devido à possibilidade de aproximação e o contato com a natureza. O contato com a natureza se consolida a partir do uso das trilhas do Silêncio, Pai Zé, Bica e do Lago.

Outras declarações feitas ao longo das entrevistas reforçam a etapa do imaginar: 
Eu acho que aqui é uma grande preservação a natureza. Quando se fala em Pico do Jaraguá... Você vem aqui e esta tudo conservado. É um lugar que a gente consegue ficar próximos da natureza, tem bastante árvore. A gente vinha subindo... Eu falei para minha filha pequena que tem bastante verde e está conservado, embora tenha algumas devastações, infelizmente tem... Mas aqui em São Paulo, é um lugar que a gente fica perto da natureza. Eu gosto daqui (Entrevistado 5).

Representa São Paulo! Eu trabalho aqui por causa do Pico, antes eu trabalhava na Vila Maria e ai surgiu uma vaga pra cá, aceitei na hora! Eu quero é natureza! Eu quero respirar... Nossa, eu chegava em casa com a cara toda preta e aqui não (Entrevistado 17).

Como Turismólogo e Geógrafo, eu acho que sendo uma área alta as pessoas tem a noção de como é tão grande a cidade e nós tão pequenos, é uma área necessária para a cidade, pois carece de áreas verdes. São Paulo é além do cotidiano, existem áreas de descanso e retiro (Entrevistado 30).

Essa mesma pergunta revelou que o imaginário do PE Jaraguá está atrelado também a um local turístico, como atrativo turístico natural e histórico e como um ponto de referência para o município de São Paulo. As declarações a seguir evidenciam esse imaginário: Uma parte histórica do Brasil, mais que um marco um espaço fundamental (Entrevistado 10); Um marco histórico e que virou um ponto turístico (Entrevistado 11).

Alguns entrevistados se referiram ao período histórico ressaltando-se a importância da região do Jaraguá como sendo um dos primeiros locais a explorarem ouro no Brasil e ser utilizado como ponto de referência por indígenas e posteriormente pelos Bandeirantes adentrarem rumo ao sertão do país (DALMO, 2003; DEAN, 1996).

Eu acho que é um dos poucos símbolos da cidade de São Paulo que é ainda, que é um símbolo da cidade, mas que é um pedaço de natureza, não é um símbolo urbano como um monumento ou alguma coisa assim. Então é bem... Aqui e a Serra da Cantareira praticamente. A verdade é o que sobrou de natureza na cidade e o Pico por ser o ponto mais alto a gente tem uma referência e isso é muito legal. $E$ fica perto de mim! (Entrevistado 8).

Esse cara viu São Paulo mudar. Esse cara estava aqui antes da gente chegar, entendeu? Ele viu toda porcaria que fizemos com o Rio Tietê e na natureza. Eu imagino como isso deveria ser lindo, mas se tudo isso não tivesse 
acontecido não estaríamos aqui hoje. Você imaginar o tamanho dessa mata, que se ligava na Cantareira (Entrevistado 22).

A etapa denominada de planejamento foi realizada, pois a própria visita ao Parque denota a sua efetivação, além da necessidade de planejamento quanto ao deslocamento e ao calculo do tempo livre disponível para a visita. Contudo, a maneira como se deu esse planejamento, suas prioridades ou entraves não foram detectados na presente pesquisa.

Quanto à etapa de concretização pode ser compreendida na seguinte pergunta: "Qual atividade você buscou fazer aqui no parque?", as respostas dadas pelos entrevistados demonstrou que buscavam o contato com a natureza, a possibilidade de beber água da nascente, ver a paisagem natural, caminhar nas trilhas, observar a magnitude da cidade de São Paulo, ver os animais silvestres e subir até o Pico do Jaraguá pela trilha do Pai Zé ou de carro pela Estada Turística do Jaraguá.

Descanso, paz, independente que o pessoal faz um pouco mais de barulho aqui, mas você consegue dar uma apagada em tudo isso e deixar só o barulho dos pássaros e sentir até o som dos gaviões e das andorinhas. Eu não venho aqui para ficar ouvindo música, ficar falando, crianças chorando, o legal é ouvir o macaquinho chamando (Entrevistado 22).

A última etapa denominada de consequência se configura como sendo o auge do Processo de Concretização do Imaginário, o individuo finalmente obtém o resultado do que foi primeiramente imaginado e posteriormente materializado na concretização.

A pergunta realizada para finalizar a entrevista remete-se a ultima etapa: "O que você sente ao entrar aqui no parque?". O entrevistado 2 declarou que sente: Paz, Harmonia, alegria, o entrevistado 5 afirmou que é: Muito agradável, você sente a sensação de livre, agradável o ambiente, uma sensação boa, muito boa!

Vale destacar a declaração do entrevistado 19 que explicou que via o Pico de longe há mais de 30 anos, e que sempre ouvia falar desse local, mas nunca tinha tido a oportunidade de visitá-lo e ao concretizar o imaginário declarou: Muita alegria, muito bom! Até que enfim conheci, gostei mesmo. Fiquei maravilhado!

Na resposta dada pelo entrevistado 8 identificou-se que o PE Jaraguá pode ser considerado uma extensão da casa do visitante, pois segundo sua declaração se sente bem ao morar próximo: É muito gostoso ainda ter um pedaço de floresta preservado aqui pertinho da gente. Eu me sinto bem por morar aqui perto, por que na cidade não tem mata nativa e sim alguns pequenos parques. Eu adoro floresta, a Mata Atlântica. 
A declaração do entrevistado 12 também reforça a teoria apresentada por Tuan (1983), tudo a nossa volta começa como espaço indiferenciado que ao longo do tempo vai se transformando em lugar à medida que conhecemos melhor e o dotamos de valor.

Estando aqui, eu sinto uma paz muito grande! Uma paz de espírito, uma paz incrível e só sente a pessoa que costuma frequentar. Você vem uma vez, você não quer deixar de vir nunca. Uma paz muito gostosa, uma paz de espírito. Uma Calma no seu interior... Estava falando isso para minha esposa. Algo maravilhoso.

Ainda segundo Tuan (1983) podemos considerar que as respostas dadas pelos entrevistados em relação ao Parque demonstram os sentimentos que sentem pelo lugar e seus pensamentos em prol da sua conservação como declarado pelo entrevistado 18: Eu me orgulho de morar por aqui, porque quem mora em São Paulo não tem acesso, sempre metrópole. Nos temos uma regalia de ter um lugar desse.

Outra pergunta relevante que complementa a analise foi "Você procura avistar o Pico de outros lugares da cidade?", essa pergunta confirma que até os dias de hoje o Pico do Jaraguá continua sendo um ponto de referência para a cidade. Lá de Osasco dá pra ver. Eu sempre olho pra cá. Eu gosto! Quando a gente passa na Rodovia Bandeirantes a gente sempre fala "Olha o Pico" (Entrevistado 21).

Olha, eu estou trabalhando ultimamente em Osasco e é impossível não olhar para cá e não ver ele. É bem visível... Até uma coisa bem engraçada, se esta perdido em algum lugar e quer se localizar... Cadê o Pico? Ai você olha e já sabe em que direção ir (Entrevistado 9).

A partir dessas declarações averiguou-se que o visitante concretizou seu imaginário em relação ao contato com a natureza, pois em todas as respostas dadas observou-se que havia uma satisfação em estar nesse local que possibilita o contato com a natureza.

Todas as declarações, em todas as etapas do Processo de Concretização do imaginário, deixaram evidente o desejo e os sentimentos positivos envolvendo a natureza, além do tempo livre dedicado ao lazer que está diretamente voltado para esse tipo de atividade.

Motivado pelo desejo de escapar das obrigações diárias e da rotina dos grandes centros urbanos, os moradores vão à busca de novas experiências, não basta estar no lugar, o individuo quer fazer parte daquela situação, ou seja, segundo Gaeta (2010) não quer mais ser um expectador. As pessoas querem ter a sensação de que viveram um momento único não captado pelas lentes de uma câmera. Sendo assim, o espaço se torna um lugar (TUAN, 1983). Neste sentido, o imaginário relacionado com o contato 
com a natureza vem a tona e motiva a busca pelo contato e por experiências em relação as áreas naturais, no caso nas UC's de proteção integral.

Como conceituado, é por meio do lazer e da atividade turística, mais especificamente o ecoturismo, que as pessoas conseguem ter acesso a esses espaços naturais, como no caso do PE Jaraguá. Neste sentido, o Parque oferece uma ambientação, equipamentos e atrativos para sanar esses anseios ligados ao contato com a natureza, como a infraestrutura básica e turística e atrativos (trilhas, mirantes, playgrounds, área para piquenique, fauna e flora). Vale ainda comentar que o Parque Estadual do Jaraguá possui funcionários qualificados para atender a demanda, mesmo que isso não foi comentado pelos entrevistados sabe-se que é um fator de importância para atender á demanda.

Portanto, o lazer permitido no PE Jaraguá é algo buscado no mundo contemporâneo, em especial pelas pessoas dos centros urbanos, que deve ser valorizado por todos. Sendo assim, o imaginário é o que torna esse tempo livre ainda mais satisfatório no sentido de concretizar seus anseios em relação ao contato com a natureza.

\section{Considerações finais}

O presente artigo aproximou o estudo do imaginário com a busca pelo contato com natureza, tendo como objeto de estudo o PE Jaraguá, uma área contribui para o equilíbrio ambiental de seu entorno e da região metropolitana de São Paulo, além de promover e auxiliar as práticas de lazer em meio a natureza.

Neste sentido, infere-se que o PE Jaraguá é um local que proporciona satisfação e cumpri o seu papel em conservar sua área e proporcionar atividades e equipamentos de lazer, mesmo com uma demanda estimada em 10.000 pessoas aos finais de semana.

A partir das pesquisas realizadas identificou-se, também, que o uso das áreas naturais para atividades de lazer e turismo estão sendo discutidas e se revelam como uma preocupação e denotam atenção tanto no meio acadêmico como entre visitantes.

Dentre as atividades realizadas no parque encontram-se as de ecoturismo que são desenvolvidas para aliar o contato com a natureza, o mínimo impacto e o uso das áreas para a diversão, desta forma, proporcionando experiências em contato com a natureza e ainda demonstra por meio de ações de educação ambiental, que a conservação desses ambientes é fundamental.

Logo, a busca pelo contato com a natureza é estimulada pelo imaginário, pois o homem sempre buscou saber o que existia nesses ambientes, ou seja, o imaginário em relação à natureza sempre existiu, por diversos motivos e estímulos que se modificaram ao longo do tempo, fato que pode ser observado no decorrer desta pesquisa.

Assim sendo, o modo de vida contemporâneo transformou a concretização desse imaginário por meio de atividades controladas (pessoal 
treinado, equipamentos de segurança, áreas demarcadas e sinalizadas), uma situação diferente daquela vivida pelos antigos exploradores, pois não tinham informações concretas sobre os recursos naturais que os cercavam, os mitos e as lendas eram motivos para adentrar nas matas ou fugir dela. Além disso, os diversos meios de comunicação disponíveis transmitem as informações cada vez mais rápidas, os avanços nas pesquisas científicas, tecnologia e a precisão de informações excluem muitos receios em relação à natureza, como tinham os primeiros exploradores e viajantes.

Em virtude disso, a presente pesquisa realizada com os visitantes do parque atingiu seu objetivo com êxito. Contudo, seu resultado foi possível a partir da elaboração do $\mathrm{PCl}$ (Processo de Concretização do Imaginário), esquema que possibilitou visualizar e entender as relações entre imaginário, lazer e natureza a partir das seguintes etapas do processo: imaginar, planejar, concretizar, e as suas consequências.

Logo, o primeiro problema de pesquisa foi respondido, mas seu resultado revelou que o imaginário é o motivador, porém está relacionado a qualquer área natural, ou seja, á natureza como um todo, e não exclusivamente ao PE Jaraguá. Todavia a visita a esse determinado parque pode ser entendida por sua localização no meio urbano, que pode ser um dos facilitadores para a busca do contato com a natureza, assim como a sua importância histórica e sua relevância como maior local de altitude da cidade de São Paulo.

Em todas as entrevistas observou-se que 0 visitante possui motivação em conhecer o parque, pois seu imaginário está associado ao contato com a natureza que proporciona paz, harmonia, alegria, bem estar e principalmente fugir da rotina diária, mesmo que por algumas horas. Neste sentido, O PE Jaraguá proporciona experiências e sensações positivas, diferentes do que no dia a dia as pessoas vivenciam.

Observou-se, principalmente pelas análises apresentadas que o PE Jaraguá com as suas características naturais atrai muitos visitantes que buscam um espaço de lazer com atividades em meio a natureza. Vale esclarecer que o distanciamento do homem em relação à natureza pode ser um dos fatores que levaram á contemplação e a um estado de idolatria das áreas naturais seja ela qual for, evidente a partir das respostas dadas pelos entrevistados.

Assim sendo, é na sociedade contemporânea que o imaginário vem a tona, nos estimulando a visitar essas áreas naturais e buscar experiências novas através da prática de atividades de lazer e ecoturismo. Todavia, identificou-se também que essas experiências em contato com a natureza possuem data e hora para acontecer, em função das obrigações e tempo de trabalho, e que os riscos são controlados e minimizados tanto pelos próprios equipamentos quanto pelos serviços dos profissionais qualificados para prestar assistência necessária.

A contemplação, a idolatria e a busca crescente pelo contato com espaços naturais, indicam que os moradores dos grandes centros urbanos desejam e necessitam de mais contato com a natureza. $O$ resgate desse contato traz consequências e sensações positivas para os visitantes, e também traz benefícios para as áreas naturais. Neste sentido, as atividades 
e experiências vividas nessas áreas despertam o interesse em conservar e preservar esses espaços, que deixam de ser um simples espaço e se tornam um lugar por ser revestido de memórias e experiências, assim são lugares naturais que participam efetivamente da vida dessas pessoas.

Deste modo, a primeira hipótese foi parcialmente confirmada, visto que o imaginário do turista/visitante é um fator motivador que se manifesta em função da busca do contato com a natureza, mas não necessariamente em relação ao PE Jaraguá.

Quanto à experiência do visitante/turista no PE Jaraguá identificouse que ela ocorre a partir das atividades de ecoturismo: contemplação da fauna e da flora e caminhada nas trilhas. Sendo que essas experiências ocorrem em diversas áreas, como na trilha do Pai Zé, trilha do Silêncio e trilha da Bica, os mirantes do Pico do Jaraguá, as áreas para piquenique, nos playgrounds destinados as crianças, e áreas de churrasqueiras.

Logo, a segunda hipótese foi confirmada, pois a sensação de fuga do cotidiano e da rotina dos centros urbanos foi comprovada nas entrevistas, onde os visitantes destacaram que a partir das experiências vivenciadas no $\mathrm{PE}$ Jaraguá, conseguiram concretizar 0 imaginado tendo como consequência sensações positivas de paz, harmonia e da fuga da rotina.

Infere-se que o imaginário participa constantemente da vida e do cotidiano, pois ele pode ser considerado um dos fatores que levam a busca por alguma experiência ou atividade, que pode trazer sensações positivas para a vida do homem. Assim sendo, o imaginário é um fator essencial na vida humana, sem o imaginário a vida não tem cor e não tem emoção.

Assim, o PE Jaraguá pode continuar e vir a ser para novos visitantes um local que possibilita o contato com a natureza pelo acesso aos equipamentos de lazer e ecoturismo, na medida em que aflore a importância da preservação e conservação dessa área para São Paulo.

O presente artigo contribui para estudos e pesquisas sobre 0 imaginário, lazer, turismo e áreas naturais, em especial os Parques Estaduais em áreas urbanas. Assim como, marca a importância e necessidade de estudos futuros mais aprofundados acerca do proposto Processo de Concretização do Imaginário e suas etapas, em especial a etapa de planejamento que não foi contemplada. A presente pesquisa também pode servir de base para o poder público quanto ao planejamento e á sustentabilidade em vista das consequências positivas para os visitantes e turistas, e também para a área natural por meio da importância, conservação e preservação das áreas naturais.

\section{Referências bibliográficas}

CAVENAGHI, A.J. Uma história ecologicamente correta. Revista Projeto História. São Paulo, v.23, nov. 2001. Disponível em: <http://revistas.pucsp.br/index.php/revph/article/view/10702>

COSTA, P.C. Unidades de Conservação: Matéria prima do ecoturismo. São Paulo: Aleph, 2002. 
DALMO, D.V. Histórico do Parque Estadual do Jaraguá. São Paulo, 2003.

DEAN, W. A ferro e fogo: A historia e a devastação da Mata Atlântica brasileira. São Paulo: Companhia das Letras, 1996.

DUMAZEDIER, J. Lazer e cultura popular. 3 ed. São Paulo: Perspectiva, 2004.

ESPIG, M.J. Ideologia, mentalidades e imaginário: cruzamentos e aproximações teóricas. Anos 90 - Revista do Programa de PósGraduação em História da Universidade do Rio Grande do Sul, Porto Alegre, n.10, dezembro de 1998. Disponível em: http://seer.ufrgs.br/anos90/article/view/6220 Acesso em: 27 de janeiro de 2012.

FFLORESTAL, Fundação para a Conservação e a Produção Florestal do Estado de São Paulo. Plano de Manejo do Parque Estadual do Jaraguá. Núcleo de Planos de Manejo. Secretaria do Estado de Meio Ambiente, 2010.

GAETA, C. Turismo de Experiência e novas demandas de formação profissional. In: NETTO, A.P.; GAETA, C. Turismo de Experiência. São Paulo: Editora SENAC São Paulo, 2010.

GAMBARÉ, B. Analise do perfil do visitante do Parque Estadual do Jaraguá. Anais do $38^{\circ}$ Encontro Nacional de Estudos Rurais e Urbanos. Faculdade de Filosofia, Letras e Ciências Humanas - Universidade de São Paulo. São Paulo, 2011.

GASTAL, S. Turismo, imagens e imaginário. 1 ed. São Paulo: Aleph, 2005.

IBGE, Instituto Brasileiro de Geografia e Estatística. Vocabulário Básico de Recursos Naturais e Meio Ambiente. 2 ed. Rio de Janeiro: IBGE, 2004. Disponível em: http://www.ibge.gov.br/home/presidencia/noticias/vocabulario.pdf. Acesso em: 06 de fevereiro de 2012.

KINKER, S. Ecoturismo e conservação da natureza em parques nacionais. Campinas, SP: Papirus, 2002.

LE GOFF, J. O imaginário medieval. Tradução Manuel Ruas. Portugal: Editorial Estampa, 1994.

MAFFESOLI, M. O imaginário é uma realidade. Revista FAMECOS, n¹5. Porto Alegre/RS, 2001. Disponível em: http://revistaseletronicas.pucrs.br/ojs/index.php/revistafamecos/article/view/3 123/2395. Acesso em: 11 de janeiro de 2012.

PIRES, P.S. Turismo e Meio Ambiente: Relação de Interdependência. In: PHILIPPI JR, A.; RUSCHMANN, D.V.M. Gestão ambiental e sustentabilidade no turismo. Barueri, SP: Manole, 2010.

SILVA, J.M. Tecnologias do imaginário: esboços para um conceito, 2003. Disponível em: http://ensino.univates.br/ clenz/tcc/GT12TB5.pdf Acesso em: 28 de janeiro de 2012. 
SMA, Secretaria do Meio Ambiente. Conhecer para conservar: as unidades de conservação do Estado de São Paulo. São Paulo: Terra Virgem, 1999.

SMA, Secretaria do Meio Ambiente. Atlas das Unidades de Conservação Ambiental do Estado de São Paulo. São Paulo: Imprensa Oficial do Estado, 2001.

SNUC, Sistema Nacional de Unidades de Conservação. 18 de julho de 2000. Disponível em: http://www.planalto.gov.br/ccivil 03/leis/L9985.htm Acesso em: 28 de dezembro de 2011.

SWARBROOKE, J. Turismo sustentável: conceitos e impacto ambiental, vol. 1 (tradução Margarete Dias Pulido). - São Paulo: Aleph, 2000.

TRIGO, L.G.G.i. A viagem como experiência significativa. In: NETTO, A. P.; GAETA, C. Turismo de Experiência. São Paulo: Editora SENAC São Paulo, 2010.

WEARING, S.; NEIL, J. Ecoturismo: impactos, potencialidades e possibilidades. 1 ed. Barueri, SP: Manole, 2001.

WUNENBURGER, J.J. O Imaginário. Tradução Maria Stela Gonçalves. Edições Loyola. São Paulo, Brasil, 2007.

TUAN, Yi-Fu. Espaço e Lugar: A Perspectiva da Experiência. Tradução de Lívia de Oliveira. São Paulo: DIFEL, 1983.

\section{Notas:}

${ }^{1}$ Ambiente de elevada pluviosidade (IBGE, 2004, p.147).

Estratos inferiores de uma floresta (SMA, 1999, p.114).

Bárbara Gambaré dos Santos: Universidade Anhembi Morumbi e Universidade Nove de Julho, São Paulo, SP, Brasil.

E-Mail: barbarajaragua@yahoo.com.br

Link para o currículo Lattes: http://lattes.cnpq.br/3380583918745767

Airton José Cavenaghi: Universidade Anhembi Morumbi, São Paulo, SP, Brasil.

E-Mail: acavenaghi@gmail.com

Link para o currículo Lattes: http://lattes.cnpq.br/8415372088403504

Data de submissão: 13 de março de 2013

Data de recebimento de correções: 27 de setembro de 2013

Data do aceite: 25 de janeiro de 2014

Avaliado anonimamente 